$\begin{array}{ll}\text { Research Square } & \begin{array}{l}\text { Preprints are preliminary reports that have not undergone peer review. } \\ \text { They should not be considered conclusive, used to inform clinical practice, } \\ \text { or referenced by the media as validated information. }\end{array}\end{array}$

\title{
Age and Cohort Trends in Disability Among Chinese Older Adults
}

\author{
Chaoping Pan ( $\sim 2513129539 @ q q . c o m$ ) \\ Wuhan University \\ $\mathrm{NaCaO}$ \\ Wuhan University \\ Mohammedhamid Osman Kelifa \\ Wuhan University
}

\section{Research Article}

Keywords: Older adults, A-P-C model, Disability, Disablement process model

Posted Date: February 23rd, 2022

DOl: https://doi.org/10.21203/rs.3.rs-1365770/v1

License: @) (1) This work is licensed under a Creative Commons Attribution 4.0 International License. Read Full License 


\section{Abstract}

Objective: This study aims to examine age and cohort trends in disability among Chinese older adults, and explore the disablement process factors that may explain the cohort trends in disability.

Methods: The study used data from five waves of the Chinese Longitudinal Healthy Longevity Study (CLHLS). A hierarchical logistic growth model was used to analyze the A-P-C effects and the contributors of cohort trends.

Results: Activity of Daily Living (ADL), Instrumental of Activity of Daily Living (IADL), and Functional Limitation (FL) among Chinese older adults showed increasing age and cohort trends. FL was more likely to result in IADL disability than ADL disability. Among the disablement process factors, gender, residence, education, health behavior, disease, and family income contributed to most of the cohort trends in disability.

Conclusions: As facing increasing disability trends among older adults, it is necessary to distinguish age and cohort trends, and develop more effective interventions according to relative contributors to prevent disability among older adults.

\section{Introduction}

In recent years, the development of the economy and medical care has largely expanded life expectancy. However, longer life expectancy also made older adults suffer more from disability. Preventing disability can reduce huge healthcare expenditures, hospitalization, and mortality rates [1]. China has the largest population of older adults in the world and is aging much faster than other countries [2]. The number of Chinese older adults has been already being over 260 million (over $18.7 \%$ of the total population) in 2020 . This may cause a large number of older adults to live with disabilities. In 2020 , more than 40 million Chinese older adults were disabled, and it was estimated that disabled older adults in China will reach 65 million in 2030 [3]. Therefore, greater research into the disability patterns and related determinants of older persons is required to develop more effective interventions to alleviate the financial burden of healthcare costs on families and society.

China's economy and health system have made great progress since the establishment of the People's Republic of China, especially after the reform and opening up in 1978. The development of the economy and health system may also affect the trends in disability [4]. For instance, more education, increased family income, and better living conditions in more recent cohorts may help older adults maintain health and live a longer life. However, older persons are more likely to live with a disability as a result of fewer children in the family, chronic disease, and an increment in life expectancy in more recent cohorts.. These unique socio-demographic changes may also have different effects on cohort trends in disability among older adults. Thus, it is necessary to separate the age and cohort effects and explore factors that may affect cohort trends in disability in the unique social background of China to improve the efficiency of health service provisions.

In the field of demography, time can be captured by three temporal dimensions: Age, Period and Cohort (A-P-C) [5]. Each aspect of A-P-C has a unique contribution to population health. Age (A) is an indicator of biological processes, which causes internal physiological changes and eventually leads to morbidity, disability, and/or death. External sources, such as accumulation of exposure, natural damage to human systems, or/and the genetic manifestation of diseases may affect the aging process. Period (B) describes morbidity, disability, or/and death at a given time, and reflects economic, sociocultural, technological and environmental factors that may influence the entire population at a given time. Cohort (C) captures the health status of successive generations who are born in a social system during a similar period of time and experience similar social experiences in their lifetime. In general, failure to distinguish A-P-C trends may lead to non-negligible bias and provide incomplete analysis of population health trends [6].

Though many studies explored the trends in disability, only several studies explored the A-P-C trends of disability among older adults [5, 7-9]. The results consistently displayed an increasing age trend. However, the period and cohort trends were more equivocal. Lin found decreasing period and cohort trends for both blacks and whites among the oldest-old in America by conducting cross-classified random effect model [5]. Lin also found a decreasing period trend and an increasing cohort trend among American people aged 70 and over in America by performing fixed effects approach [9]. A study conducted in Hong Kong showed an increasing period trend of ADL disability and no cohort effect among Chinese older adults [8]. Zhang indicated an increasing period trend and a decline cohort trend among the oldest-old in China by using intrinsic estimator method [7]. However, this study was focused on the oldest-old, which was too old to represent the older population in China. The difference in cultural context, age, indicators of disability, or methods used in the analysis may account for the inconsistent results of previous studies. So, further study is still needed to explore the A-P-C trends in disability among Chinese older adults.

\section{Theoretical Framework}

The disablement process model proposed by Verbrugge and Jette in 1994 may help us understand the process involved in disability [10]. According to the disablement process model, disease, including chronic disease and mental health, is the primary stage of the disability process. Disease results in impairment and functional limitation, and functional limitation eventually results in disability. Risk factors and accommodating factors will affect the disablement process. The disablement process model is widely used to explore the influencing factors of disability among old adults [11, 12]. As disability changes over time, disablement process factors may also affect the trends in disability. However, few studies used the disablement process model to explore related factors that affect the trend in disability, especially A-P-C trends in disability.

According to previous studies, disability, defined as difficulties in the performance of socially defined roles and tasks, is commonly measured by Activity of Daily Living (ADL) and Instrumental of Activity of Daily Living (IADL) and reflects the Functional Limitation (FL) in real-life contexts. FL refers to functional capacity independent of the situational requirement. Recently, more researchers recognized that FL may improve the evaluation of disability [13, 14]. According to disablement process model, many factors could affect the disability trends. For instance, risk factors contain demographic factors and health 
behaviors. Demographic factors included gender, education, and so on [11, 12]. Health behaviors contained smoking, excising, and so on [15]. Accommodating factors included social supports (e.g., spouse, living arrangement, household income, Social Participation (SP)), and so on [16, 17]. Disease included chronic disease and mental health [18]. However, few studies used these variables to explain the cohort trends in disability, especially using multiple indicators of disability.

The current study aims to examine age and cohort trends in disability among Chinese older adults and explore the disablement process factors that may explain the cohort trends in disability by analyzing survey data from five waves of the Chinese Longitudinal Healthy Longevity Study (CLHLS).

\section{Methods}

\section{Study Design and Participants}

This study draws on data from 5 waves $(2005,2008,2011,2014$, and 2018) of the Chinese Longitudinal Healthy Longevity Survey (CLHLS). To ensure sample representativeness, the CLHLS randomly selected 23 out of 31 provinces in China, which covered $85 \%$ of the total population in China. In the survey, individuals aged 65 and over were investigated, and the baseline number of participants in 2005 was 15638. Survey details were provided elsewhere [16, 19]. As there were only a few respondents older than 106 years old, this study only focused on individuals 65 to 105 years old. After excluding those older than 105 years, the numbers of respondents in each wave were as follows: wave 2005, n=15613; wave 2008, $n=16563$; wave 2011, $n=9679$; wave 2014, $n=7107$; wave $2018, n=15771$.

In the analysis of longitudinal data, participant attrition is an issue of particular concern. In this study, intermittent missing data was assumed as missing at random (MAR), and the Multiple Imputation (MI) method was applied to deal with the missing values of independent variables. We also included alive, dead, or lost to follow-up as a categorical variable into the growth A-P-C model to control for any bias due to these statuses.

\section{Dependent variables}

ADL was measured at each wave using six items (dressing, bathing, indoor transferring, toileting, continence, and feeding). Participants were asked if they needed assistance with each of the six activities. Individuals were defined as having ADL disability if they needed assistance in performing at least one of the six daily activities.

IADL was composed of eight items (shopping, visiting neighbors, washing clothes, making food, walking $1 \mathrm{~km}$, crouching and standing [repeated three times], carrying $5 \mathrm{~kg}$ weight, and taking public transport). Respondents were categorized as having IADL disability if they needed help in performing at least one of the eight items.

FL was formed by five items: (a) stand up from sitting in a chair, (b) hand behind neck, (c) hand behind lower-back, (d) able to pick up a book from the floor, (e) hold-up arms. Older adults unable to do at least one of the five items were treated as having FL and were coded as 1 , and those who were able to do all the items were coded as 0.

\section{Independent variables}

\section{Time variables}

Age (65 years and above) was taken as a continuous variable and included in the model after mean-centralization to facilitate interpretation of the intercept. The birth cohorts were established by subtracting individual ages from the survey years and were treated as a categorical variable. The values were grouped into 5-year groups (1906-1910 to 1941-1945 years). Those who were born before 1909 or after 1945 years were combined into one group to get enough group members.

\section{Disease}

Disease included chronic disease and mental health. Chronic disease was a count of self-reported health conditions (ranging from 0 to 12 ), including diabetes, hypertension, cancer, arthritis, respiratory diseases (bronchitis, emphysema, pneumonia and asthma), tuberculosis, stroke, cataract, duodenal ulcer, glaucoma, bedsore, and Parkinson's disease.

Mental health was measured by three items, including "look on the bright side of things", "keep my belongings neat and clean" and "be happy when younger". Each question was assessed on four grades: always (0), often (1), sometimes (2), seldom (4), and rarely or never (5). The score for mental health ranged from 0 to 12 , with a higher score representing worse mental health.

\section{Risk factors and accommodating factors}

Risk factors included demographic factors (gender and education) and health behaviors (smoking and drinking). Men (coded as 0 ) and women (coded as 1 ) represented gender. Education was measured by years of education. We classified Smoking by Smoking (coded as 1) or not (coded as 0 ), and classified excise by exercise (coded as 1 ) or not (coded as 0$)$.

Accommodating factors included social supports, and were measured by co-residence, marital status, family income, and SP. Co-residence was categorized as living alone (coded as 0 ) and not living alone (coded as 1). Marital status was defined as having a spouse (coded as 1) and not having a spouse (coded as 0 ). Family income was divided into seven levels: 0 9999 yuan, 10000 19999 yuan, 20000 29999 yuan, 30000 39999 yuan, 40000 49999 yuan, and 50000 yuan and above (coded as 5), respectively coded 0 to 5. SP was assessed by asking participants the following questions; "do you play cards/mah-jongg at 
present?", "do you take part in some social activities at present?" and "do you travel beyond home county?". The total score was 0 to 3 , with a higher score representing a better SP.

\section{Data Analysis}

Many methods can analyze the A-P-C effects, such as tntrinsic estimation, generalized constrained estimation, cross-classified random effect model, and hierarchical logistic model [5-7]. In this study, A-P-C effects were analyzed using a hierarchical logistic growth model, which can be employed in the analysis of longitudinal data and does not require specific constraints. We conducted a series of hierarchical logistic models to examine the age and cohort trends and explored related factors, in which age, residence, co-residence, marital status, smoking, exercising, chronic disease, and mental health were all included in level 1 part of the model as time-varying variables. Cohort, gender, education, and attrition (alive, dead or lost to follow-up) were included in the level 2 part of the model as time-invariant variables. The Square term of age was used to estimate the nonlinear effects of age. Cohort was included as a categorical variable. Consistent with most previous studies, period was not included in the model due to the collinearity of age, period, and cohort effects [6]. The model is shown below.

Level 1:

$$
\ln \left(\frac{P_{i j}}{1-P_{i j}}\right)=\beta_{0 j}+\beta_{1} \text { age }_{i}+\beta_{2} \text { age }_{i}{ }^{2}+\sum_{k=3}^{\mathrm{K}} \beta_{k} \text { covariate }_{k i}
$$

Level 2:

$$
\beta_{0 j}=\Pi_{0}+\gamma_{01} \operatorname{cohort}_{1 j}+\sum_{q=2}^{Q} \gamma_{0 \mathrm{q}} \text { covariate }_{q j}+c_{0 j}
$$

To explore the contribution of each element in the disablement process, we added the variables into the model separately. We compared the OR values before and after including the variables in the model and then estimated the contribution of each variable. [6].

\section{Results}

\section{Descriptive characteristics}

The Sample descriptive characteristics based on cohorts are shown in Table 1. The results showed that older adults in more recent cohorts suffered less from $A D L, I A D L$, and FL disabilities. Individuals were younger in more recent cohorts. Women had a higher proportion than men in earlier cohorts, which was narrowed in more recent cohorts. The proportion of urban older adults increased from $44 \%$ in 1905 and earlier cohorts to $52 \%$ in 1946 and subsequent cohorts. In more recent cohorts, older adults had better mental health, higher income, higher SP, better education. They smoked and exercised more as well. Greater proportions of respondents have a spouse in more recent cohorts. 
Table 1

The Sample descriptive characteristics based on cohorts

\begin{tabular}{|c|c|c|c|c|c|c|c|c|c|c|}
\hline Variables & $\begin{array}{l}1905 \text { and } \\
\text { before }\end{array}$ & 1906-2010 & $\begin{array}{l}1911- \\
1915\end{array}$ & $\begin{array}{l}1916- \\
1920\end{array}$ & $\begin{array}{l}1921- \\
1925\end{array}$ & $\begin{array}{l}1926- \\
1930\end{array}$ & $\begin{array}{l}1931- \\
1935\end{array}$ & $\begin{array}{l}1936- \\
1940\end{array}$ & $\begin{array}{l}1941- \\
1945\end{array}$ & $\begin{array}{l}1946 \\
\text { aftel }\end{array}$ \\
\hline ADL & $0.56(0.50)$ & $0.50(0.50)$ & $0.38(0.48)$ & $0.35(0.48)$ & $0.24(0.43)$ & $0.17(0.37)$ & $0.11(0.31)$ & $0.07(0.25)$ & $0.05(0.21)$ & 0.04 \\
\hline IADL & $0.98(0.15)$ & $0.95(0.95)$ & $0.91(0.28)$ & $0.86(0.35)$ & $0.77(0.42)$ & $0.66(0.47)$ & $0.50(0.50)$ & $0.36(0.48)$ & $0.29(0.45)$ & 0.21 \\
\hline $\mathrm{FL}$ & $0.81(0.40)$ & $0.75(0.75)$ & $0.67(0.47)$ & $0.59(0.49)$ & $0.48(0.50)$ & $0.39(0.49)$ & $0.28(0.45)$ & $0.20(0.40)$ & $0.16(0.37)$ & 0.14 \\
\hline Age & $100.45(4.56)$ & 99.51(99.51) & $95.44(4.13)$ & $92.52(5.18)$ & $88.00(4.79)$ & $83.49(5.05)$ & 78.34(5.10) & 73.57(5.14) & $71.55(3.80)$ & 68.4 \\
\hline Gender & $0.81(0.39)$ & $0.73(0.73)$ & $0.62(0.48)$ & $0.58(0.49)$ & $0.52(0.50)$ & $0.50(0.50)$ & $0.50(0.50)$ & $0.49(0.50)$ & $0.47(0.50)$ & 0.47 \\
\hline Education & $0.16(0.36)$ & $0.19(0.19)$ & $0.28(0.45)$ & $0.32(0.47)$ & $0.37(0.48)$ & $0.44(0.50)$ & $0.50(0.50)$ & $0.61(0.49)$ & $0.72(0.45)$ & 0.78 \\
\hline Residence & $0.44(0.50)$ & $0.40(0.49)$ & $0.44(0.50)$ & $0.49(0.50)$ & $0.44(0.50)$ & $0.46(0.50)$ & $0.48(0.50)$ & $0.49(0.50)$ & $0.48(0.50)$ & 0.52 \\
\hline Smoke & $0.08(0.27)$ & $0.09(0.09)$ & $0.12(0.33)$ & $0.15(0.35)$ & $0.17(0.37)$ & $0.19(0.39)$ & $0.21(0.41)$ & $0.24(0.42)$ & $0.24(0.43)$ & 0.22 \\
\hline exercise & $0.16(0.37)$ & $0.18(0.18)$ & $0.21(0.41)$ & $0.24(0.43)$ & $0.27(0.44)$ & $0.33(0.47)$ & $0.39(0.49)$ & $0.41(0.49)$ & $0.40(0.49)$ & 0.41 \\
\hline $\begin{array}{l}\text { Chronic } \\
\text { disease }\end{array}$ & $0.70(0.90)$ & $0.71(0.71)$ & $0.73(0.88)$ & $0.80(0.92)$ & $0.90(0.98)$ & $0.99(1.03)$ & $1.01(1.01)$ & $1.03(1.03)$ & $1.04(1.02)$ & 1.06 \\
\hline $\begin{array}{l}\text { Mental } \\
\text { health }\end{array}$ & $4.44(1.75)$ & $4.48(4.48)$ & $4.43(1.79)$ & $4.33(1.81)$ & $4.34(1.84)$ & $4.22(1.89)$ & $4.06(1.91)$ & $3.99(1.92)$ & $3.90(1.86)$ & 3.89 \\
\hline $\begin{array}{l}\text { Family } \\
\text { income }\end{array}$ & $0.73(1.24)$ & $1.28(1.28)$ & $1.27(1.61)$ & $1.56(1.76)$ & $1.59(1.78)$ & $1.62(1.81)$ & $1.56(1.83)$ & $1.59(1.81)$ & $2.13(1.88)$ & 2.58 \\
\hline SP & $0.10(0.35)$ & $0.13(0.13)$ & $0.18(0.46)$ & $0.23(0.53)$ & $0.30(0.59)$ & $0.39(0.67)$ & $0.49(0.73)$ & $0.59(0.79)$ & $0.68(0.83)$ & 0.79 \\
\hline $\begin{array}{l}\text { Living } \\
\text { alone }\end{array}$ & $0.91(0.28)$ & $0.89(0.89)$ & $0.84(0.36)$ & $0.84(0.37)$ & $0.81(0.39)$ & $0.80(0.40)$ & $0.81(0.39)$ & $0.85(0.36)$ & $0.86(0.34)$ & 0.90 \\
\hline $\begin{array}{l}\text { Having a } \\
\text { spouse }\end{array}$ & $0.03(0.18)$ & $0.06(0.06)$ & $0.11(0.31)$ & $0.16(0.37)$ & $0.27(0.45)$ & $0.39(0.49)$ & $0.51(0.50)$ & $0.63(0.48)$ & $0.70(0.46)$ & 0.78 \\
\hline
\end{tabular}

Note: Standard errors are in parentheses.

[Insert Table1 here]

Figure 1 displays the age trends of ADL, FL and IADL disabilities, which increased from $0.003,0.046$ and 0.044 in age 65 years to $0.329,0.719$ and 0.955 in age 105 years, respectively. Overall, the age trend of IADL disability was the highest among the three kinds of disabilities, followed by FL disability, and the age trend of ADL disability was the lowest.

[Insert Fig. 1 here]

Figure 2 displays the cohort trends of ADL, FL, and IADL disabilities, with 0 to 9 representing the 1905 years and before cohorts to 1946 years and subsequent cohorts, respectively. The results showed that the cohort trends of ADL, FL and IADL disabilities increased from 0.029, 0.201, and 0.509 in the 1905 and earlier cohorts to $0.147,0.406$ and 0.748 in the 1946 and later cohorts, respectively. Overall, the cohort trend of IADL disability was the highest among the three types of disabilities, followed by FL disability, and ADL disability had the lowest cohort trend.

[Insert Fig. 2 here]

Table 3 shows the contributions of disablement process factors to cohort trends in ADL, IADL and FL disabilities. As for risk factors, gender have considerable contributon to disability, and negatively contributed to cohort trends in FL and IADL disability, and the contributions decreased from - $14.7 \%$ and - $347.1 \%$ in the 1906-2010 cohort to $-9.9 \%$ and $-21.7 \%$ in the 1946 and afterward cohorts. Except for the 1906-2010 cohort, residence also had sizable contributions, and positively contributed to the cohort trends in ADL disability among older adults, and the contributions increased from $3.3 \%$ in the $1911-1915$ cohort to $17.8 \%$ in 1946 and later cohorts. Education were also an important contributors and negatively contributed to the cohort trends in disability, and overall, the contributions were larger in more recent cohorts. Health behaviors also significantly contribute to cohort trends in disability. Smoking positively contributed to the disability trend, and the contributions to FL and ADL increased from 5.6\% and 3.3\% in the $1906-2010$ cohort to $9.8 \%$ and $7.4 \%$ in the 1946 and subsequent cohorts, and the contributions (except for 1906-2010 cohort) to IADL increased from 5.1\% in the 1911-1915 cohort to $14.5 \%$ in the 1946 and afterward cohorts. Exercise positively contributed to the cohort trends in ADL and IADL disability, and the effects of IADL disability decreased from 135.3-11.4\%.

Exercise also negatively contributed to the cohort trend in FL disabilities, and the contributions increased from - 1.4\% in the $1906-2010$ cohort to $-24.5 \%$ in the 1946 and after cohort. Overall, chronic disease positively contributed to the increment of cohort trends in disability, and the contribution had increased from $0.7 \%,-0.7 \%$ and $0.0 \%$ in the $1906-2010$ cohort to $30.0 \%, 26.0 \%$, and $38.5 \%$ in the 1946 and later cohorts. Mental health relatively had few contributions to cohort trends in disability. As for accommodating factors, family income had a positive contribution to the increment of cohort trend in ADL disability but a negative contribution to cohort trends in FL and IADL disabilities. Having a spouse showed negative effects on ADL disability in the earlier cohorts and then turned into a positive one, from $52.9 \%$ to $-12.3 \%$. Living arrangement and SP had relatively minor contributions to cohort effects in disability. 
Table 3

The contributions of disablement process factors to ADL, IADL and FL disabilities trends

\begin{tabular}{|c|c|c|c|c|c|c|c|c|c|c|c|}
\hline \multirow[t]{2}{*}{ Cohorts } & \multicolumn{5}{|c|}{ Risk factors } & \multicolumn{2}{|c|}{ Disablement process } & \multicolumn{4}{|c|}{ Accommodating factors } \\
\hline & Gender & Residence & Education & Smoking & exercise & $\begin{array}{l}\text { Chronic } \\
\text { disease }\end{array}$ & $\begin{array}{l}\text { Mental } \\
\text { health }\end{array}$ & $\begin{array}{l}\text { Living } \\
\text { arrangement }\end{array}$ & $\begin{array}{l}\text { Having a } \\
\text { spouse }\end{array}$ & $\begin{array}{l}\text { Family } \\
\text { income }\end{array}$ & SP \\
\hline \multicolumn{12}{|c|}{ FL (ref: 1905 and before) } \\
\hline $\begin{array}{l}1906- \\
2010\end{array}$ & -0.147 & 0.007 & -0.014 & 0.056 & -0.022 & 0.007 & 0.147 & -0.007 & 0.028 & -0.308 & 0.035 \\
\hline $\begin{array}{l}1911- \\
1915\end{array}$ & -0.134 & -0.002 & -0.059 & 0.006 & -0.066 & -0.002 & 0.008 & -0.016 & 0.022 & -0.198 & 0.043 \\
\hline $\begin{array}{l}1916- \\
1920\end{array}$ & -0.116 & -0.007 & -0.062 & 0.004 & -0.088 & 0.046 & -0.033 & -0.012 & 0.012 & -0.228 & 0.034 \\
\hline $\begin{array}{l}1921- \\
1925\end{array}$ & -0.126 & -0.005 & -0.060 & 0.019 & -0.129 & 0.104 & -0.019 & -0.016 & -0.012 & -0.265 & 0.044 \\
\hline $\begin{array}{l}1926- \\
1930\end{array}$ & -0.105 & -0.009 & -0.082 & 0.031 & -0.134 & 0.163 & -0.042 & -0.021 & -0.026 & -0.292 & 0.031 \\
\hline $\begin{array}{l}1931- \\
1935\end{array}$ & -0.085 & -0.011 & -0.093 & 0.050 & -0.114 & 0.216 & -0.070 & -0.024 & -0.040 & -0.341 & 0.028 \\
\hline $\begin{array}{l}1936- \\
1940\end{array}$ & -0.090 & -0.015 & -0.153 & 0.066 & -0.108 & 0.261 & -0.082 & -0.022 & -0.054 & -0.387 & 0.012 \\
\hline $\begin{array}{l}1941- \\
1945\end{array}$ & -0.104 & -0.016 & -0.230 & 0.077 & -0.134 & 0.295 & -0.101 & -0.021 & -0.078 & -0.458 & -0.016 \\
\hline $\begin{array}{l}1946 \text { and } \\
\text { after }\end{array}$ & -0.099 & -0.018 & -0.245 & 0.098 & -0.159 & 0.300 & -0.076 & -0.018 & -0.070 & -0.473 & -0.048 \\
\hline \multicolumn{12}{|c|}{ ADL (ref: 1905 and before) } \\
\hline $\begin{array}{l}1906- \\
2010\end{array}$ & -0.023 & -0.069 & 0.000 & 0.033 & 0.092 & -0.007 & 0.056 & -0.003 & 0.003 & 0.246 & 0.013 \\
\hline $\begin{array}{l}1911- \\
1915\end{array}$ & -0.042 & 0.033 & -0.005 & 0.009 & 0.119 & -0.005 & 0.011 & -0.057 & 0.004 & 0.225 & 0.026 \\
\hline $\begin{array}{l}1916- \\
1920\end{array}$ & -0.034 & 0.068 & -0.006 & 0.006 & 0.098 & 0.028 & -0.012 & -0.033 & 0.003 & 0.211 & 0.020 \\
\hline $\begin{array}{l}1921- \\
1925\end{array}$ & -0.042 & 0.057 & -0.006 & 0.016 & 0.114 & 0.090 & -0.002 & -0.055 & -0.005 & 0.240 & 0.028 \\
\hline $\begin{array}{l}1926- \\
1930\end{array}$ & -0.035 & 0.085 & -0.008 & 0.028 & 0.099 & 0.154 & -0.013 & -0.068 & -0.010 & 0.268 & 0.021 \\
\hline $\begin{array}{l}1931- \\
1935\end{array}$ & -0.024 & 0.116 & -0.009 & 0.043 & 0.087 & 0.191 & -0.029 & -0.069 & -0.014 & 0.291 & 0.021 \\
\hline $\begin{array}{l}1936- \\
1940\end{array}$ & -0.028 & 0.139 & -0.016 & 0.051 & 0.083 & 0.230 & -0.033 & -0.066 & -0.018 & 0.319 & 0.005 \\
\hline $\begin{array}{l}1941- \\
1945\end{array}$ & -0.033 & 0.154 & -0.024 & 0.056 & 0.101 & 0.248 & -0.047 & -0.061 & -0.024 & 0.354 & -0.014 \\
\hline $\begin{array}{l}1946 \text { and } \\
\text { after }\end{array}$ & -0.040 & 0.178 & -0.028 & 0.074 & 0.114 & 0.260 & -0.041 & -0.060 & -0.021 & 0.382 & -0.028 \\
\hline \multicolumn{12}{|c|}{ IADL (ref: 1905 and before) } \\
\hline $\begin{array}{l}1906- \\
2010\end{array}$ & -3.471 & 0.000 & -0.706 & 0.647 & 1.353 & 0.000 & 1.471 & -0.235 & 0.529 & -3.176 & 0.588 \\
\hline $\begin{array}{l}1911- \\
1915\end{array}$ & -0.674 & -0.005 & -0.274 & 0.051 & 0.312 & -0.014 & 0.093 & -0.065 & 0.107 & -0.563 & 0.228 \\
\hline $\begin{array}{l}1916- \\
1920\end{array}$ & -0.421 & -0.007 & -0.201 & 0.026 & 0.208 & 0.087 & 0.019 & -0.035 & 0.052 & -0.492 & 0.130 \\
\hline $\begin{array}{l}1921- \\
1925\end{array}$ & -0.342 & -0.006 & -0.153 & 0.050 & 0.206 & 0.156 & 0.038 & -0.035 & -0.012 & -0.474 & 0.131 \\
\hline $\begin{array}{l}1926- \\
1930\end{array}$ & -0.276 & -0.007 & -0.191 & 0.061 & 0.161 & 0.229 & -0.002 & -0.041 & -0.044 & -0.493 & 0.098 \\
\hline $\begin{array}{l}1931- \\
1935\end{array}$ & -0.227 & -0.009 & -0.204 & 0.088 & 0.129 & 0.281 & -0.033 & -0.040 & -0.060 & -0.543 & 0.094 \\
\hline $\begin{array}{l}1936- \\
1940\end{array}$ & -0.220 & -0.010 & -0.311 & 0.107 & 0.108 & 0.334 & -0.039 & -0.036 & -0.088 & -0.597 & 0.055 \\
\hline
\end{tabular}




\begin{tabular}{|c|c|c|c|c|c|c|c|c|c|c|c|}
\hline \multirow[t]{2}{*}{ Cohorts } & \multicolumn{5}{|c|}{ Risk factors } & \multicolumn{2}{|c|}{ Disablement process } & \multicolumn{4}{|c|}{ Accommodating factors } \\
\hline & Gender & Residence & Education & Smoking & exercise & $\begin{array}{l}\text { Chronic } \\
\text { disease }\end{array}$ & $\begin{array}{l}\text { Mental } \\
\text { health }\end{array}$ & $\begin{array}{l}\text { Living } \\
\text { arrangement }\end{array}$ & $\begin{array}{l}\text { Having a } \\
\text { spouse }\end{array}$ & $\begin{array}{l}\text { Family } \\
\text { income }\end{array}$ & SP \\
\hline $\begin{array}{l}1941- \\
1945\end{array}$ & -0.234 & -0.012 & -0.433 & 0.118 & 0.131 & 0.372 & -0.061 & -0.034 & -0.128 & -0.687 & 0.020 \\
\hline $\begin{array}{l}1946 \text { and } \\
\text { after }\end{array}$ & -0.217 & -0.013 & -0.469 & 0.145 & 0.114 & 0.385 & -0.044 & -0.031 & -0.123 & -0.721 & -0.040 \\
\hline
\end{tabular}

[Insert Table 3 here]

\section{Sensitive Analysis}

Figure 3 shows the age trends in disability which was not controlled for the cohort effect. Compared with the results regarding the age trends in disability of Fig. 1, the results of Fig. 3 show a higher disability level at age 65 years and a lower increasing rate. Figure 4 shows the results of the cohort trends in disability without controlling for the age effect. The results in Fig. 4 show declining cohort trends, while the results in Fig. 2 show increasing cohort trends. These results indicated that neglecting cohort or age effect can cause significant bias when estimating time trends in disability.

[Insert Fig. 3 here]

[Insert Fig. 4 here]

\section{Discussions}

This study explored Age and cohort trends in Disability and related factors among Chinese older adults. We found increasing age and cohort trends in ADL, IADL and FL disabilities. More specifically, the age trend in FL was lower than IADL but higher than ADL. We also found that IADL disability and FL began earlier than $A D L$ disability. The results were consistent with other studies $[19,20]$. According to the disablement process model, FL finally leads to $A D L$ and IADL disabilities[10]. In this study, the results further indicated that FL was more likely to result in IADL disability than ADL disability. Our results have policy implications, health policies such as Health China Action (2019-2030) should pay more attention to identifying and reducing FL to prevent disabilities, especially IADL disability.

Older adults in more recent cohorts suffered more from disabilities after controlling for age and other disablement process factors. The result was inconsistent with Zhang's studies conducted in China, which found decreasing cohort trends in disabilities[7]. Two reasons may explain the inconsistent results: one is because a different method was used to estimate the A-P-C model. Zhang's study used an IE estimator, while the current study used the hierarchical logistic model. The other may be Zhang's study focused on the oldest-old while our study focused on older adults younger than those in Zhang's study. According to our study, health policies such as long-term health insurance should increase the financial supports for older adults in a younger cohort. In our study, we found decreasing trends in disabilities in descriptive analysis and sensitivity analysis, the main reason was that the age effect was not be controlled for and younger age was more likely to be in earlier cohorts.

Based on the disablement process model, we further explored the contributors of cohort trends in disabilities. As for demographic factors, gender negatively contributed to cohort trends in IADL disabilities and FL, which was consistent with other study[15]. We also found that the contributions decreased in more recent cohorts. The improvement of the social-economic status of women that benefited more from the reduction of disability among older adults in the earlier cohorts may explain the result. Hence, health services should pay more attention to the health demands of older women in earlier cohorts. Residence positively contributed to the cohort trends in ADL disability among older adults, and the contributions were larger in more recent cohorts. The development of urbanization has expanded the gap between urban and rural public resources. This calls for more equitable distribution of health resources between rural and urban areas. Education reduced the increasing trends in disability, which was consistent with other study[21]. What's more, we also found the negative contributions were larger in more recent cohorts. This may be because older adults in more recent cohorts obtained more education, and have more health resources or health knowledge to maintain functional health in later life. So, more health services should be provided for older adults in earlier cohorts.

As for health behaviors, drinking positively contributed to the cohort trends in disability with larger contributions in more recent cohorts. Exercise negatively contributed to the cohort trends in FL disability, and the effect was larger in more recent cohorts. The results were inconsistent with Chen and Frank's study, which only found minor contributions of health behavior to disability trends[15]. The difference may be caused by Chen and Frank only using two-time point data. Older adults were more likely to smoke and exercise in more recent cohorts, which may explain these results. However, exercise also positively contributed to cohort trends in ADL and IADL disabilities, and the contributions increased in more recent cohorts. This outcome could be due to the fact that disabled older adults were more likely to change their unhealthy lifestyles. So, health policies such as Health China Action (2019-2030) should promote exercise in older adults in earlier cohorts and reduce smoking in more recent cohorts.

As for social supports, family income showed the largest contribution to cohort trends in IADL and ADL disability, which had a negative contribution to cohort trends in IADL disabilities but a positive contribution to the increment of cohort trend in ADL disability. The results were inconsistent with Zajacova's studies, which only found declining trends in economic status, which were associated with increasing disability prevalence[21]. The reason may be because Zajacova's study did not distinguish between ADL and IADL disabilities. Current results may be because higher family income was more likely to prevent mild disability (FL or IADL disability), while it can only maintain the lives of older adults with severe disability (ADL disability). The results indicated that families should provide timely support to prevent a mild disability of older adults. Overall, the contributions of family income were larger in more recent cohorts. Results could

Page $7 / 11$ 
be explained by the rising family income in more recent cohorts. As older adults had low family incomes, health services, such as Integrated Medical and Nursing services, should be provided more affordably to older adults, especially in earlier cohorts. It is also necessary to promote the establishment of longterm care insurance in China to provide supports for less severe disabilities and eventually improve the functional health of older adults and reduce the longterm care burden of the family. We only found minor contributions of living arrangement to cohort trends in disabilities and increasing negative contribution of having a spouse, which may be caused by few numbers of children in the family and increasing of "empty-nest" older adults in more recent cohorts. So, policies should encourage children (e.g. providing allowances or tax benefits to children living with their parents) to live with their parents in the future.

For the disablement process, we found chronic disease positively contributed to the escalations of cohort trends in disabilities. Previous studies showed that chronic disease had a large effect on disability trends among older adults[18, 22], which is consistent with the results of our study. Increases in chronic disease in more recent cohorts may explain this result. According to our studies, health policies such as Health China Action (2019-2030) should conduct interventions to chronic disease in more recent cohorts to prevent disability among older adults.

\section{Limitations And Strengthens}

This study has several limitations. First, as longitudinal data was used in our study, the period effect was not included in the A-P-C analysis. However, as our study focused on the older adults, the span of the period was much shorter than age and cohort, so the effect of period could be trivial and omitted from the model[6]. Second, although we used longitudinal data, we were still unable to isolate the causal direction of related factors of cohort trends in functional health, such as exercise and family income. Third, the measurement of functional health is from self-reported surveys, which may cause bias. However, selfreported data are commonly used in disability research of older adults, which can reflect personal status interacting with the real world more accurately[23]. Finally, our study only calculated the total contributions of each disablement process factor, which did not explore the relationships between these contributions. So, more studies are needed to explore the mechanism of the contributions.

Nonetheless, this study contributes to the existing literature in four aspects. First, this study used a five-wave national representative longitudinal data in a developing country, which allows to better investigate age and cohort trends in disability and explore contributors of cohort trends in disability. Second, it is conducted in the Chinese context, which fills the gap of lacking A-P-C analysis beyond the developed countries. Third, this paper combined ADL, IADL, and FL to study age and cohort trends in disability and related contributors of cohort trends in disability, which can better reveal the disability trends and related contributors of disabilities. Finally, we also added the disablement process model by revealing the age and cohort trends in disability and the contributions of disablement process factors to cohort trends in disability.

\section{Conclusions}

Our study has several implications for policy, practice, and research: First, in light of the declining fertility rate and the rapidly aging society, our study showed the likelihood of disability has increased in both age and cohort trends. This requires society to pay more attention to reducing functional health among older adults. Second, our study gauged the relative importance of the disablement process factors in explaining cohort trends in disability, necessitating more precise interventions to reduce functional health among older adults. Finally, our study divided temporal trends into two dimensions, age, and cohort, and explored various effects of relevant factors on cohort trends in disability, which may invoke further research in this area across different cultural contexts and populations.

\section{Declarations}

\section{Ethical approval and consent to participate}

Not applicable.

\section{Consent for publication}

Not applicable.

\section{Availability of data and materials}

The datasets used and/or analysed during the current study are available from the corresponding author on reasonable request.

\section{Competing interests}

The authors declared no potential conflicts of interest concerning the research, authorship and/or publication of this article.

\section{Funding}

None reported.

\section{Authors' contributions}

C.P. conceived, designed, and analyzed the data and was responsible for the interpretation of findings, primary drafting of the manuscript, and revisions. N.C. and M.O.K. made substantial contributions to the interpretation of data and revising the manuscript critically for important intellectual content. All authors read and approved the final manuscript. 
Not applicable

\section{References}

1. Luppa M, Luck T, Weyerer S, Konig HH, Brahler E, Riedel-Heller SG: Prediction of institutionalization in the elderly. A systematic review. Age and Ageing 2010, 39:31-38.

2. Feng J, Wang Z, Yu Y: Does long-term care insurance reduce hospital utilization and medical expenditures? Evidence from China. Social Science \& Medicine 2020, 258

3. Zheng X, Pang L, Chen G, Huang C, Liu L, Zhang L: Challenge of population aging on health. Berlin, Germany: Springer; 2016.

4. Liang YJ, Song AQ, Du SF, Guralnik JM, Qiu CX: Trends in Disability in Activities of Daily Living Among Chinese Older Adults, 1997-2006: The China Health and Nutrition Survey. Journals of Gerontology Series a-Biological Sciences and Medical Sciences 2015, 70:739-745.

5. Lin SF, Beck AN, Finch BK: Black-White Disparity in Disability Among U.S. Older Adults: Age, Period, and Cohort Trends. Journals of Gerontology Series BPsychological Sciences and Social Sciences 2014, 69:784-797.

6. Yang Yang, Land KC: Age-Period-Cohort Analysis: New Models, Methods, and Empirical Applications. Boca Raton, FL: Chapman and Hall/CRC; 2013.

7. Zhang P-D, Lv Y-B, Li Z-H, Yin Z-X, Li F-R, Wang J-N, Zhang X-R, Zhou J-H, Wu X-B, Duan J, et al: Age, Period, and Cohort Effects on Activities of Daily Living, Physical Performance, and Cognitive Functioning Impairment Among the Oldest-Old in China. Journals of Gerontology Series a-Biological Sciences and Medical Sciences 2020, 75:1214-1221.

8. Yu R, Wong M, Chang B, Lai X, Lum CM, Auyeung TW, Lee J, Tsoi K, Lee R, Woo J: Trends in activities of daily living disability in a large sample of community-dwelling Chinese older adults in Hong Kong: an age-period-cohort analysis. Bmj Open 2016, 6.

9. Lin SF, Beck AN, Finch BK, Hummer RA, Master RK: Trends in US Older Adult Disability: Exploring Age, Period, and Cohort Effects. American Journal of Public Health 2012, 102:2157-2163.

10. Verbrugge LM, Jette AM: The disablement process. Soc Sci Med 1994, 38:1-14.

11. Martin LG, Zimmer Z, Lee J: Foundations of Activity of Daily Living Trajectories of Older Americans. J Gerontol B Psychol Sci Soc Sci 2017, 72:129-139.

12. Yu HW, Chen DR, Chiang TL, Tu YK, Chen YM: Disability trajectories and associated disablement process factors among older adults in Taiwan. Arch Gerontol Geriatr 2015, 60:272-280.

13. Botoseneanu A, Allore HG, de Leon CFM, Gahbauer EA, Gill TM: Sex Differences in Concomitant Trajectories of Self-Reported Disability and Measured Physical Capacity in Older Adults. Journals of Gerontology Series a-Biological Sciences and Medical Sciences 2016, 71:1056-1062.

14. Rector JL, Marceau K, Friedman EM: Moderation of the Association Between Chronic Medical Conditions and Functional Limitations Over Time by Physical Activity: Effects of Age. Journals of Gerontology Series a-Biological Sciences and Medical Sciences 2020, 75:168-174.

15. Chen YQ, Sloan FA: Explaining Disability Trends in the US Elderly and Near-Elderly Population. Health Services Research 2015, 50:1528-1549.

16. Gao M, Sa Z, Li Y, Zhang W, Tian D, Zhang S, Gu L: Does social participation reduce the risk of functional disability among older adults in China? A survival analysis using the 2005-2011 waves of the CLHLS data. BMC Geriatr 2018, 18:224.

17. Yoshida D, Ninomiya T, Doi Y, Hata J, Fukuhara M, Ikeda F, Mukai N, Kiyohara Y: Prevalence and Causes of Functional Disability in an Elderly General Population of Japanese: The Hisayama Study. Journal of Epidemiology 2012, 22:222-229.

18. Kail BL: Marital Status as a Moderating Factor in the Process of Disablement. Journal of Aging and Health 2016, 28:139-164.

19. Zimmer Z, Martin LG, Nagin DS, Jones BL: Modeling Disability Trajectories and Mortality of the Oldest-Old in China. Demography 2012, 49:291-314.

20. Pan C, Kelifa MO, Liang J, Wang P: Joint trajectories of disability and related factors among older adults in China. Public Health 2021, 199:96-102.

21. Zajacova A, Montez JK: Explaining the increasing disability prevalence among mid-life US adults, 2002 to 2016. Social Science \& Medicine 2018, 211:18.

22. Schellekens JJ: Explaining Disability Trends in the United States, 1963-2015. Population and Development Review 2019, 45:819-+.

23. Smith KV, Goldman N: Measuring Health Status: Self-, Interviewer, and Physician Reports of Overall Health. Journal of Aging and Health 2011, 23:242266.

\section{Figures}




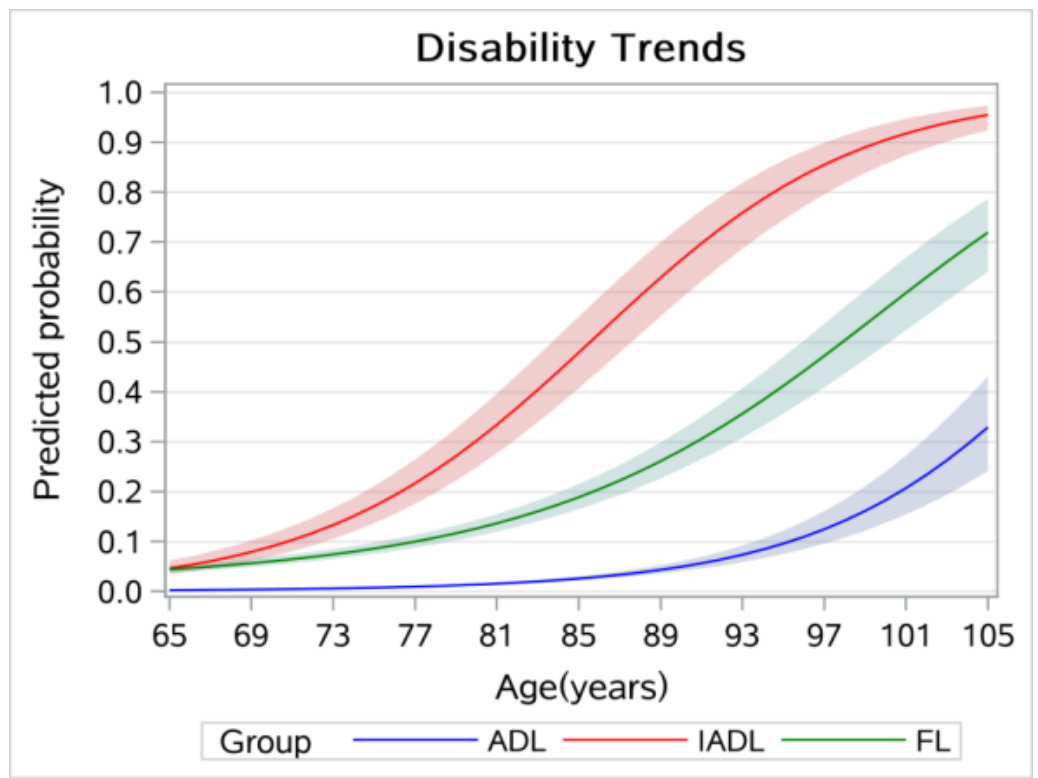

Figure 1

cohort trends in disabilities among older adults

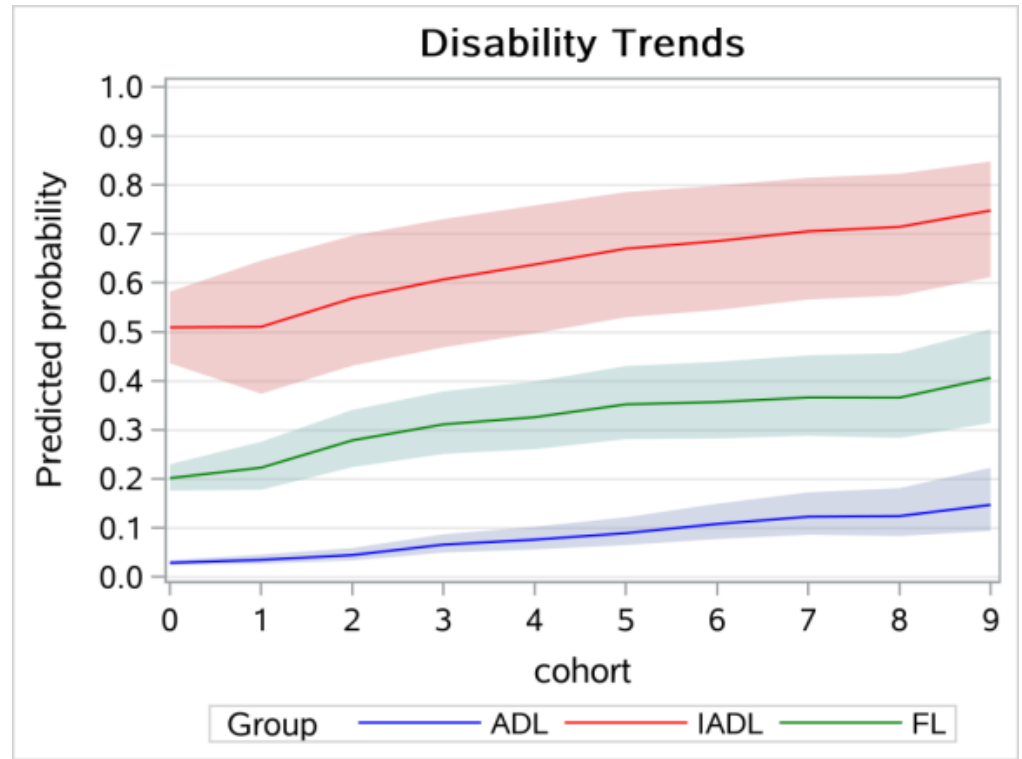

Figure 2

cohort trends in disabilities among older adults 


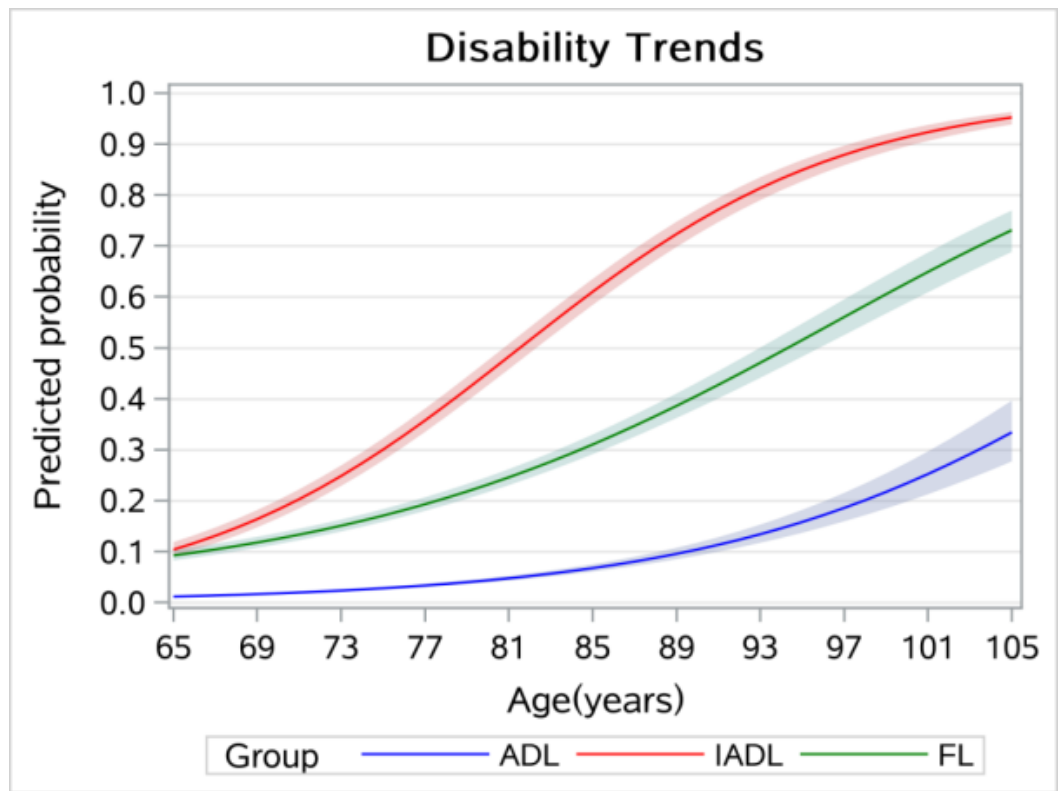

Figure 3

Age trends in disability without controlling for cohort effects

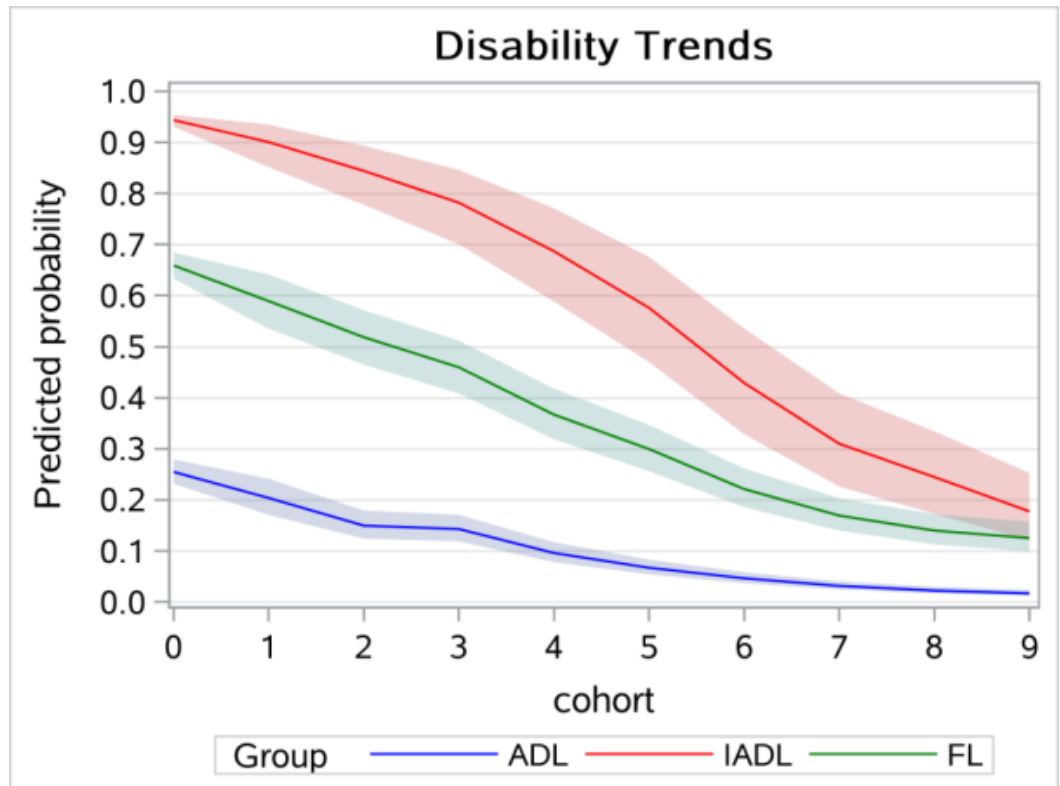

Figure 4

Cohort trends in disability without controlling for age effects 